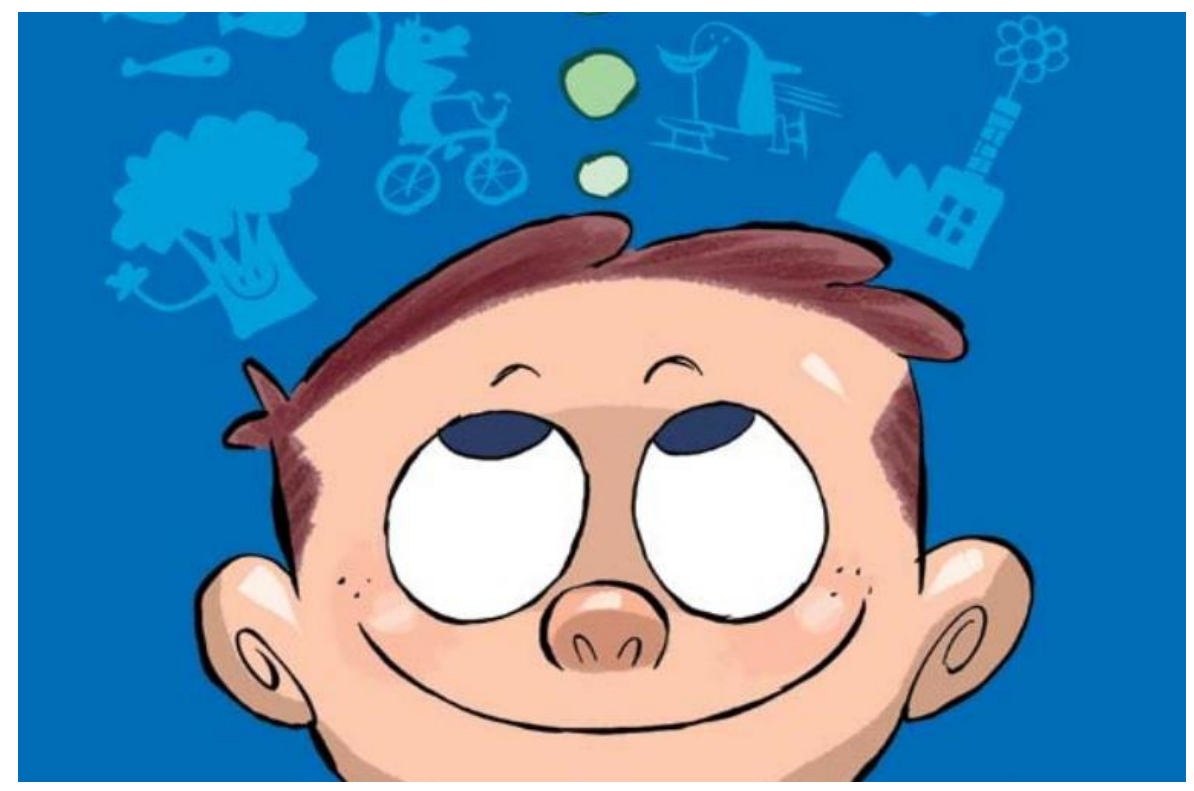

\title{
Pedagogização do espaço urbano
}

Pedagogization of urban space

\section{Mariza Vieira da Silva* Claudia Castellanos Pfeiffer ${ }^{* *}$}

Resumo: A partir do dispositivo teórico da Análise de Discurso, propomos uma reflexão sobre o funcionamento do discurso científico, quando mobilizado no espaço específico de sua divulgação, com vistas a um objetivo pedagógico: a prática da divulgação científica. Procuramos mostrar, em nossa reflexão e análise, por meio da textualidade de cartilhas temáticas, o modo como vai se construindo uma sustentação para os sentidos da relação entre o homem e o meio ambiente, na indistinção de argumentos, configurados por um discurso científico e um discurso moral, projetando no indivíduo a responsabilidade pela sua preservação, por meio de uma alteração de comportamento. Na individualização da solução para os problemas advindos das assim designadas "alterações do homem sobre a natureza", apaga-se a história, apaga-se o político, apaga-se a ação do Estado e as contradições inerentes ao atual jogo de forças políticas e econômicas.

Palavras-chave: Cartilhas, meio ambiente, divulgação científica, Análise de Discurso.

Abstract: From the theoretical device of the Discourse Analyses, we pose an account about the organization of the scientific discourse within the specific boundaries of its dissemination, with a pedagogical aim: the practice of scientific publication. We aim to demonstrate, in our reflection and analysis of the textuality on theme primers, how the foundations for the meanings of the relationship between men and the environment are built in the blurriness of arguments arranged by a scientific discourse and a moral discourse, engraving in the individual the responsibility for preservation by means of a behavioural change. In the individualisation of the solution to the problems originated from the so called "men's change upon nature", history is effaced, politics is effaced, the State enterprise and the inherent contradictions to the current play of political and economic powers are effaced.

Keywords: Primes, environment, popular science, Discourse Analysis.

\footnotetext{
* Professora Doutora da Escola de Educação e Ciências Humanas - Curso de Letras. Universidade Católica de Brasília. EPTCT Q.S.7, Lote 1 - 719660-900 - Águas Claras - Distrito Federal - Brasil. marizavs@uol.com.br

** Pesquisadora Doutora do Laboratório de Estudos Urbanos do Nudecri/Unicamp. Rua Caio Graco Prado, 70. CEP: 13087-930. Cidade Universitária Zeferino Vaz. Campinas/SP - Brasil. E- mail: claupfe@yahoo.com. Processo Fapesp 2008/58160-05
} 


\section{Introdução}

Temos trabalhado, em nosso percurso de pesquisas, sobre algumas das formas por meio das quais vai se dando a relação entre o Estado e a Ciência, tendo como referência o espaço escolar, espaço este reservado, por uma memória discursiva republicana, para educar o indivíduo quanto às formas de sociabilidade que lhe garantam a cidadania, o direito de estar na rua - espaço público - de modo adequado.

Uma dessas formas se materializa na textualidade das cartilhas, primeiramente restritas ao espaço da Escola e, atualmente, sobretudo nas duas últimas décadas, alargada ao espaço das políticas públicas do Estado (SILVA, 2014). Ao tomarmos a discursividade das cartilhas como ancoragem de análise, preocupamo-nos, especificamente, em buscar compreender o funcionamento do discurso de divulgação de conhecimentos científicos na escola e na sociedade, observando como se dão as relações que se estabelecem entre ciência e ideologia, e, mais propriamente, o modo pelo qual o Estado se apropria desses conhecimentos, incidindo em uma das formas de disciplinarização dos cidadãos, própria à injunção da forma-sujeito jurídica (Pêcheux, 1990). Desse modo, ler e escrever em sociedade - ação gerida por um Estado republicano - pode se dar por meio de um instrumento linguístico e pedagógico específico como o da cartilha. Instrumento que permite a gestão das "coisas a saber" (Pêcheux, 1990), participando da configuração de um sujeito urbano escolarizado (Pfeiffer, 2001).

Nossa reflexão incidirá, pois, sobre o funcionamento do discurso científico quando mobilizado no espaço específico de sua divulgação com vistas a um objetivo pedagógico, recortando, para tanto, uma textualidade muito própria deste funcionamento: cartilhas temáticas cujo público alvo, hoje, extrapola o aluno da rede formal de ensino, marcando um modo muito singular de determinar formas de pertencimento ao Estado: uma pedagogização da vida em sociedade (SILVA, 2014), em que se trabalha a formação do cidadão em um processo contínuo e específico de apropriação do conhecimento. A prática pedagógica, lembremos, produz respostas a demandas da sociedade, através de instrumentos, técnicas e tecnologias, que são transmitidos de geração a geração, que legislam em matéria de aprender-saber, visando à conformação, adaptação, reprodução de relações sociais (HERBERT/PÊCHEUX, 2011). 
Nossa análise tem como referencial teórico e metodológico a Análise de Discurso $^{1}$, uma teoria e um instrumento de leitura e de interpretação de textos, que pressupõe a relação constitutiva entre língua, história e sujeito. As cartilhas são tomadas, pois, como objetos discursivos que, em condições de produção próprias de uma conjuntura sócio-histórica dada, estabelecem uma relação determinada entre história, sujeito e conhecimento. Elas produzem e trabalham uma textualidade, retomando e construindo espaços de memória em que estão presentes as cartilhas de alfabetização, através das quais se estabelecem as primeiras relações de um sujeito urbano escolarizado com a escrita, com a leitura, com a interpretação. Levamos em consideração, assim, que o texto, unidade imaginária de análise, tem uma relação com outros textos - intertextualidade - e o dito significa em relação ao não-dito, mas também em relação a um já-dito - o interdiscurso, uma memória discursiva de ordem não cronológica e inconsciente. É por isso que compreendemos a formulação, o dito em uma situação dada, como tendo, pois, uma historicidade. Há, portanto, condições de produção a serem explicitadas e analisadas e que deixam seus vestígios na forma material da língua.

A questão que norteou nosso trabalho foi a de como o discurso científico sobre o "meio ambiente" que circula em nossa sociedade, através de cartilhas, um instrumento linguístico-pedagógico, produz efeitos de sentido e efeitos leitor. O material de análise, recortado, de um corpus mais amplo, incidiu sobre uma cartilha dirigida mais diretamente a um público escolar e outras, dirigidas a cidadãos brasileiros.

\section{Escola e Urbanização - condições de produção das cartilhas escolares}

A Escola é uma instituição gerida em suas grandes diretrizes pelo Estado, marcada por realidades complexas e contraditórias, e que se caracteriza por colocar em jogo práticas, teorias, metodologias e tecnologias em relação às demandas dos diferentes grupos sociais de uma dada sociedade. A Escola é uma instituição da modernidade, em que se dão confrontos e alianças de forças, que não são individuais, nem universais, mas que se organizam em determinadas materialidades, produzindo efeitos de sentido, efeitos ideológicos. A Escola, mesmo não tendo permanecido idêntica a si mesma, torna-se parâmetro e referência para construir e avaliar todas as

\footnotetext{
${ }^{1}$ Nossas referências teóricas, em termos de filiações fundadoras da construção da Análise de Discurso, remetem a Pêcheux e Orlandi, sobretudo.
} 
demais formas de educação, produzir relações entre trabalho e educação, tendo peso decisivo no desenvolvimento e reprodução do modo de produção capitalista.

O século XVI, nas sociedades europeias, é um marco, nesse processo, de uma configuração sócio-histórica particular para a Escola, em uma conjuntura de reorganização do campo político e religioso, de instauração de uma ordem urbana a que o sujeito devia submeter-se, e que exigia o estabelecimento de novas formas de relação social entre sujeitos de diferentes classes. Essa "forma escolar" vai ser marcada por um modo de organizar e colocar em funcionamento o espaço e o tempo, ou seja, a escola como um lugar separado daqueles próprios a outras relações e práticas sociais, e um tempo que divide o saber por idade, por classes, por séries, por anos, por atividades, estabelecendo uma cadeia progressiva de conhecimentos a serem aprendidos e de dificuldades a serem superadas, conforme uma hierarquização de capacidade, vontade, esforço individuais. Uma unidade dividida desigualmente entre sujeitos.

Desenvolve-se, pois, um processo complexo de assujeitamento, de individuação desse sujeito urbano escolarizado, que podemos observar analisando, por exemplo, o aprender-saber escolar, as políticas públicas de educação, a legislação educacional, as teorias, metodologias e tecnologias, como as cartilhas de ensino de primeiras letras. A escolarização de todas as crianças nos centros urbanos torna-se um empreendimento de ordem pública, que cria condições para que o sujeito se submeta livremente ao Estado. Não uma submissão a pessoas, mas a regras comuns para todos no cotidiano escolar, a uma verdade pautada em uma razão universal (VINCENT, LAHIRE E THIN, 1994). Uma subordinação em que está sempre presente a relação entre ignorância e ciência, entre o sujeito que ignora algo (tudo?) e o sujeito que domina um conhecimento capaz de tirá-lo da ignorância.

Ao observar esse processo no Brasil, em sua dimensão histórica, podemos fazer alguns recortes para explicitar a produção de sentidos que aí se dá para o conhecimento e para a constituição da posição sujeito de conhecimento. No século XVI, as escolas de ler, escrever e contar são construídas no Brasil como escolas de catecúmenos, em que "Poucas letras bastariam aqui, porque tudo é papel branco e não ha que fazer outra cousa, sinão escrever á vontade as virtudes mais necessarias e ter zelo em que seja

\footnotetext{
2 "Forma escolar" é um conceito que aparece no fim dos anos 1970, na França, em trabalhos conduzidos de uma perspectiva da sociologia histórica, a partir do uso que dele faziam historiadores como Roger Chartier, Dominique Julia e Marie-Madeleine Compère, de forma a romper com uma historiografia presa a etimologias. Ver Vincent, Lahire e Thin, 1994.
} 
conhecido o Creador destas suas creaturas" (NÓBREGA, 1988, p. 94), como parte de um projeto linguístico-cultural da colonização - um projeto político articulado e conduzido principalmente pelos jesuítas, e que tem como um dos objetos de ensino da doutrina e da língua, os catecismos ${ }^{3}$. Na segunda metade do século XVIII, o Marquês de Pombal expulsa os jesuítas de Portugal e das colônias portuguesas e, dentre outras medidas, promove uma reforma pedagógica de amplo alcance, tornando obrigatório o uso da língua portuguesa e a aprendizagem do latim através do vernáculo português, na Metrópole; e, no Brasil, tornando obrigatório o ensino e o uso do português, de forma a inibir o uso de outras línguas que não a portuguesa, desencadeando, um processo de secularização do trabalho missionário (com a implantação de aulas régias), e de laicização da escola de catecúmenos em direção à escola de ler, escrever e contar.

Nesse contexto, é que podemos observar a passagem do uso dos catecismos para o das cartilhas, visando à separação entre o ensino religioso, sob a responsabilidade da Igreja, e o ensino do ler e escrever como uma atribuição do Estado. Trata-se, pois, de passar para o Estado o controle da educação, principalmente, levando em conta a economia, o desenvolvimento do comércio e da indústria nas cidades, o que se faz pela construção, principalmente, de um discurso jurídico - uma legislação educacional -, que permite a manutenção da monarquia (VOJNIAK, 2012). Será o início de um trabalho de constituição do português como uma língua nacional una, imaginariamente, a ser ensinada nas escolas da Metrópole e da Colônia, e de uma posição de um sujeito de direito.

O século XIX, como mostra uma vasta produção acadêmico-científica na área de História das Ideias Linguísticas, desencadeada por um projeto internacional entre Brasil e França ${ }^{4}$, vê a consolidação desse processo, no contexto mais amplo da gramatização (Auroux, 1992) do Português do Brasil, distinto do Português de Portugal, em que se busca, dada a conjuntura histórico-social, a construção de uma língua e de uma literatura nacionais, o estabelecimento de instituições, como a Escola, capazes de lhes conferir legitimidade e criar espaços de circulação de instrumentos e tecnologias, de outras práticas linguístico-sociais.

É, neste século, que se institui, então, uma “forma escolar" brasileira, ou seja, a construção de uma configuração histórica particular em termos de processo de escolarização, como um modelo possível de transmissão do saber; em que a relação

\footnotetext{
${ }^{3}$ Mais sobre essa questão pode ser lido em Silva (1998).

${ }^{4}$ Para conhecer o Programa de Pesquisa, consultar a página http://www.unicamp.br/iel/hil/
} 
entre o sujeito que ignora e o sujeito que sabe irá se estabelecer, de diferentes modos, em uma sociedade marcada pela colonização e pela escravidão, em que a universalização da escola básica, é importante lembrar, não faz parte do projeto da classe burguesa brasileira de então (FRIGOTTO, 2007). Nessa conjuntura, a cartilha, principalmente a partir da segunda metade do século XIX, torna-se material didático fundamental para a iniciação dos brasileiros no mundo da escrita e de acesso a um saber sobre a língua, para a construção de um imaginário sobre o que seja aprender a ler e a escrever, conferindo uma identidade para os conhecimentos linguísticos e para o sujeito - escolarizado ou não.

Conforme Mortatti, em se tratando de cartilhas de alfabetização:

Embora já na segunda metade do século XIX encontrem-se cartilhas produzidas por brasileiros, o impulso nacionalizante nessa área se faz sentir, especialmente em alguns estados, a partir da década de 1890, solidificando- se nas primeiras décadas do século XX, quando se observa o engendramento de fenômenos correlatos: apoio de editores e especialização de editoras na publicação desse tipo de livro didático; surgimento de um tipo específico de escritor didático profissional - o professor; e processo de institucionalização da cartilha, mediante sua aprovação, adoção, compra e distribuição às escolas públicas, por parte de órgãos dos governos estaduais (MORTATTI, 2000, p. 42).

A partir dos anos de 1980, sob a influência de determinadas teorias dos campos da Psicologia e da Educação, embora a cartilha passe a ser desautorizada como instrumento adequado à alfabetização, ou ao letramento, elas continuam a ser usadas no cotidiano escolar, ou emprestam sua estrutura e funcionamento a atividades propostas por professores 5 . Embora criticada e considerada como "um livro efêmero, que se desatualiza com muita velocidade”, conforme afirmação de Antonio Augusto Gomes Batista (1999), citado por Vojniak (2012, p. 35), vemos que, no Brasil, tal afirmação não se confirma, pois há um trabalho da memória aí funcionando, em termos de inscrição da criança na sociedade, em relação à língua, que individualiza este sujeito enquanto cidadão de uma sociedade capitalista urbana e letrada. E é desse trabalho de memória, do interdiscurso, que se alimenta parte do imaginário que sustenta a produção

\footnotetext{
${ }^{5}$ É, ainda, Mortatti (2000) quem nos diz que esses questionamentos resultaram no "paradoxo da produção de cartilhas "construtivistas" ou "socioconstrutivistas" ou "sociointeracionistas"; na convivência destas com cartilhas tradicionais, nas indicações oficiais e nas estantes dos professores, muitos dos quais alegam tê-las apenas para consulta quando da preparação de suas aulas; e no ensino e aprendizagem do modelo de leitura e escrita veiculado pelas cartilhas, mesmo quando os professores dizem seguir uma "linha construtivista" ou "interacionista" e seus alunos não utilizam diretamente esse instrumento em sala de aula" (p.47).
} 
massiva de cartilhas para a divulgação e circulação da informação e do conhecimento em nossa sociedade para os seus cidadãos, sejam eles crianças, jovens ou adultos.

Althusser (1980), em seu trabalho sobre os aparelhos ideológicos do Estado, mostra como a Escola, o principal desses aparelhos, assegura a reprodução da força de trabalho, pela competência e pela qualificação, que se produz pela divisão técnica e social do trabalho de forma que cada sujeito possa ocupar determinado lugar na estrutura social. A Escola é, pois, uma Instituição do Estado em que se ensina-aprende saberes práticos e, ao mesmo tempo, comportamentos, costumes ou, dizendo discursivamente, é um espaço-tempo de um saber-fazer em que se dão processos de individuação do sujeito na relação com a escrita e com o conhecimento. Quanto a isso, Pêcheux \& Gadet (2011) chamam a nossa atenção para a interpretação funcionalista que se deu ao termo "reprodução", presente no texto de Althusser, como a de "repetição eterna de um estado idêntico de coisas", bem como à noção de "ideologia". Para esses autores, a ideologia do ponto de vista das "relações de reprodução", em uma perspectiva marxista, implica em considerá-la também "do ponto de vista da resistência à reprodução, ou seja, da perspectiva de uma multiplicidade de resistências e revoltas heterogêneas que se entocam na ideologia dominante, ameaçando-a constantemente" (Idem, ibidem, p. 96).

Podemos, então, pensar que essa tomada de um instrumento linguísticopedagógico e, ao mesmo tempo, um objeto discursivo, para a divulgação da informação e do conhecimento em nossa sociedade, como a cartilha, implica em um trabalho de memória que "produz efeitos ideológicos que emergem da dominação e que trabalham contra ela por meio das lacunas e das falhas no seio dessa própria dominação" (Idem, ibidem, p. 97).

\section{O meio ambiente e as cartilhas temáticas}

Nesse caminho de exploração, e não de solução de contradições que sustentam esse jogo, podemos, no âmbito desse trabalho, avançar nossa reflexão e análise em algumas direções, que se articulam: 1. a escrita produz textos, trazendo para a cena enunciativa (MAINGUENEAU, 1989) a leitura e o sujeito, que lê, que interpreta; 2. a Escola será um dos lugares a regular e controlar a divisão desse trabalho de interpretação para/entre sujeitos; 3 . a cartilha de alfabetização desencadeia a construção de uma relação entre língua e conhecimento: entre o sujeito que sabe "a" língua e o sujeito que sabe "sobre" a língua, que desliza, nessas outras cartilhas temáticas 
contemporâneas, para o sujeito que não tem conhecimento sobre determinado domínio de conhecimento e o sujeito que detém esse conhecimento e é capaz de ensiná-lo.

Em se tratando de cartilhas de divulgação da informação e do conhecimento necessárias à vida em sociedade desse sujeito urbano escolarizado, como essas questões se apresentam? No Prefácio de uma cartilha dirigida a idosos, produzida pelo Ministério Público de São Paulo (2013), podemos observar o lugar que esse instrumento adquire em nossa sociedade.

Para que o direito ao medicamento seja real é muito importante, portanto, que nós consigamos encontrá-lo nos lugares de distribuição. E para isso, cada um de nós precisa saber onde encontrar o medicamento de que necessita. É isso o que faz esse GUIACARTILHA: nos ensina o lugar mais perto onde encontrar o medicamento. Assim, caso ele não esteja disponível, nosso pedido à Justiça já poderá orientar na busca do responsável pela falha administrativa cometida. É por essa razão que quero cumprimentar o Ministério Público do Estado de São Paulo pela iniciativa e pelo brilhante trabalho realizado, que, ao ajudar os usuários do sistema de saúde, ajuda também todos os profissionais do direito que vêm enfrentando a responsabilidade de assegurar a realização das políticas públicas capazes de atender o direito de todos a um medicamento seguro, eficaz e acessível. Sueli Gandolfi Dallari. Professora, Universidade de São Paulo (p. 8-9 - grifos nossos)

Esse lugar de ensinamento, muitas vezes, se faz através de "dicas": uma palavra categorizada como um brasileirismo pelos dicionários, ou seja, um termo próprio do Português do Brasil: "informação ou indicação boa" (HOUAISS, online). Nesse sentido, podemos observar, por exemplo, em uma cartilha elaborada pelo SENAC - Serviço Nacional de Aprendizagem Comercial, regional de Minas Gerais, denominada MEIO AMBIENTE - Dicas de atitudes conscientes e sustentáveis, que essa informação ou indicação boa, ou "nova, pouco conhecida" (FERREIRA, 1975, p. 472), dirige-se a algo que diz respeito ao próprio sujeito, como lhe sendo desconhecido, devendo, portanto, fazer parte do aprendizado: suas atitudes.

Esse trabalho pedagógico de educação de comportamentos é uma constante. Em uma Cartilha para Consumidores, vol. 3 (2011), elaborada pelo Ministério do Meio Ambiente, com "Orientações sobre o consumo consciente e redução do uso de sacolas plásticas para consumidores", como fruto da Campanha "Saco é um saco", encontramos na Apresentação: 
As cartilhas pretendem demonstrar como cada ator social, gestor municipal, pequeno e grande empresário, e cidadãos pode se engajar neste movimento, multiplicando ao seu redor a proposta de redução de sacolas plásticas, colaborando de forma efetiva para a qualidade de vida, a saúde e o bem estar de sua comunidade (p. 5 - grifos nossos).

Interessante observar que nesse processo de individuação do sujeito, independentemente de a quem a cartilha se dirija - cidadão comum, gestor, empresário -, todos devem ocupar a posição sujeito de consumidor consciente, um lugar definido em uma determinada formação social. Temos, pois, uma discursividade funcionado em que estão apagadas "as dissimetrias e dissimilaridades entre os agentes do sistema de produção", o que não se dá de forma explícita, uma vez que o processo pelo qual o sujeito é colocado em tal lugar - consumidor consciente - é apagado (Henry, 1990). Essas questões indicam que não se trata de uma situação de comunicação entre o autor e o leitor dessas cartilhas; não se trata de uma transmissão de informação, mas de um efeito de sentidos entre os interlocutores, de um discurso em funcionamento em sua relação com a exterioridade também discursiva. Nesse sentido, não se trata de presenças físicas de um homem genérico, a-histórico. A hipótese de Pêcheux (1990) é a de que esses lugares estão representados nos processos discursivos em que são colocados em jogo, não como "feixe de traços objetivos", mas, sim, "representados, isto é, presentes, mas transformados; em outros termos, o que funciona nos processos discursivos é uma série de formações imaginárias que designam o lugar que A e B se atribuem cada um a si e ao outro, a imagem que eles fazem de seu próprio lugar e do lugar do outro" (Pêcheux, 1990, p. 82); bem como do lugar do referente, ou seja, daquilo sobre o qual se fala.

A análise da cartilha, que se segue, irá nos ajudar a compreender esse movimento de diferentes discursividades, em que se produzem sentidos e se constituem posições sujeito e seus efeitos ideológicos.

\subsection{A Cartilha sobre a Conferência RIO + 20}

Analisaremos aqui o funcionamento da cartilha elaborada pelo INPE - Instituto Nacional de Pesquisas Espaciais, em maio de 2012, na ocasião em que muito se discutia e esperava-se da Conferência RIO + 20 que aconteceria em junho do mesmo ano. Apesar de não encontrarmos no título uma relação direta com as "mudanças climáticas', a cartilha vai na direção de mostrar que a relação do homem com o meio ambiente vem 
ocasionando, cumulativamente, consequências que afetam este meio ambiente, sendo, particularmente, uma destas consequências, as alterações no clima tão noticiadas e presentes em diferentes espaços discursivos como o do cinema, da literatura e dos artigos científicos.

A Cartilha intitula-se Cartilha Ilustrada sobre Economia Verde, Desenvolvimento Sustentável e Erradicação da Pobreza, tendo como subtítulo: $O$ Futuro que Queremos, nome que dá título ao documento zero da reunião das Nações Unidas. E é sobre o subtítulo que iniciamos nossas análises, pois é ele que é destacado em letras garrafais na capa da cartilha, lembrando que estaremos lidando com a opacidade dos sentidos. É pensando com Pêcheux (1969) - a língua serve para comunicar e para não comunicar -, e com Orlandi (2001) - relações sociais são, do ponto de vista discursivo, relações de sentido -, que nos permitimos suspender a evidência da chamada do documento zero divulgada e referendada pela cartilha do INPE cujo público leitor é o aluno/professor do Ensino Fundamental.

Nesse sentido, perguntamos, na opacidade do subtítulo "O Futuro que Queremos": Nós quem? Querem este "nós" o quê? O que se diz e o que se apaga nesse objeto do querer: o futuro? É preciso saber para querer, o que é preciso saber? É preciso poder para querer, quem pode? É nesse sentido, nessa trilha de compreensão, que seguirão nossos gestos de descrição e interpretação dessa Cartilha.

Retomemos, primeiramente, a imagem que vem na Cartilha, após a capa.

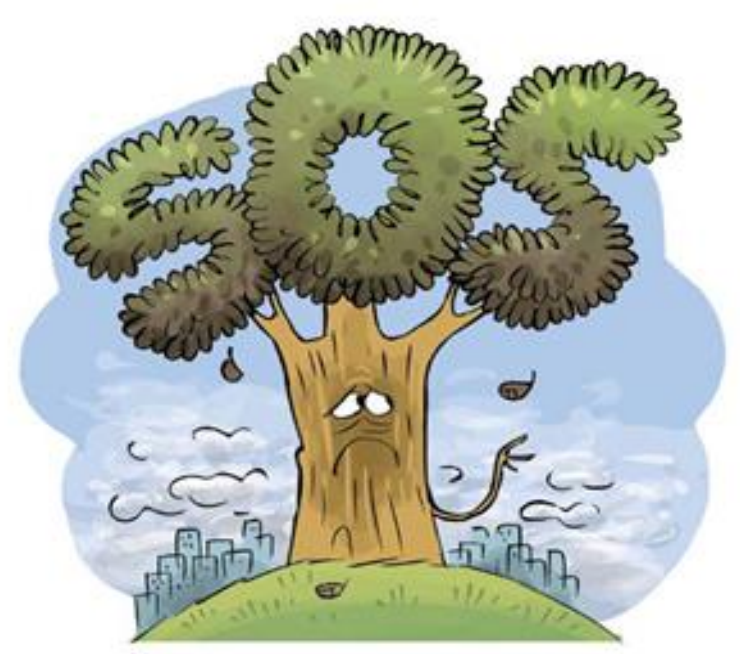


Esta imagem, enquanto materialidade significante, configura e materializa uma direção discursiva muito própria às discussões em torno das mudanças climáticas e do meio ambiente: a natureza pede socorro, uma natureza sozinha - aparentemente o homem não está presente nesta imagem - e sem voz que, paradoxalmente, pela intermediação do homem, pode ser socorrida. Uma natureza encarnada em uma árvore com dois traços humanos: a figuração de um rosto (triste, assustado) e a tecnologia da escrita, inscrita nas folhagens da árvore. O contraponto da solidão mediada é o fundo da cidade, metaforizada por um aglomerado de prédios e pelas nuvens que se confundem com a poluição (a cidade anedótica). Há, de nosso ponto de vista, um primeiro gesto de dicotomização nessa discursividade: homem/natureza; dicotomização que funciona na contradição da aparente ausência do homem quando a referência é feita à natureza. Desse modo, encontramos a estabilidade que separa o homem da natureza e, por extensão, do meio ambiente, mas que, entretanto, não pode escapar da contradição constitutiva que incide na impossibilidade dessa separação, materializada na mediação necessária inscrita no rosto e nas letras da árvore.

Prossigamos em nosso trajeto narrativo-discursivo. A Cartilha, logo após esta imagem, começa a traçar uma narrativa sobre a história dos encontros mundiais que já aconteceram a respeito de questões ambientais que giraram em torno do assim chamado efeito estufa, Lembremo-nos de que estamos falando de uma cartilha que busca situar a $\mathrm{RIO}+20$ a qual faz parte desta série de encontros, cujo nome faz referência direta, no caso específico brasileiro, às duas décadas posteriores ao encontro da ECO 92. Nesta narrativa, cujo subtítulo é "Tudo começou em Estocolmo", encontramos:

A partir da década de 1950, verificou-se um grande crescimento econômico em quase todo o mundo. A atividade industrial foi impulsionada por vários fatores, dentre eles o crescimento populacional e a consequente ampliação do número de consumidores de produtos industrializados. Essa expansão aumentou significativamente a poluição atmosférica e o uso dos recursos naturais da Terra.

A consciência de que a degradação ambiental por ações humanas poderia causar impactos e alterações profundas na vida do planeta levou a ONU (Organização das Nações Unidas) a organizar, em 1972, a Conferência de Estocolmo.

O encontro, que reuniu representantes de diversos países na capital da Suécia, foi a primeira iniciativa mundial no sentido de organizar as relações entre o Homem e o Meio Ambiente. Ao final da conferência foi divulgado um Manifesto Ambiental com 19 princípios de comportamento e responsabilidade, que deveriam conduzir as decisões em relação às questões ambientais (p. 4 - grifos nossos). 
Nesta textualidade, encontramos uma forte regularidade que sustenta a dicotomização sobre a qual comentávamos mais acima, com um acréscimo: o homem (que não faz parte da natureza, nem do meio ambiente, portanto) é o responsável por ações que deterioram esta natureza, agindo sobre o meio ambiente, impactando os recursos naturais. Nesta discursividade, o homem não é um recurso, mas o responsável por afetar os recursos, porque promove alterações profundas na vida do planeta. Desta posição discursiva, 'planeta' é um objeto natural, assim designado por um discurso científico, que o neutraliza politicamente. As alterações, desse lugar discursivo acarretam na degradação ambiental, colocando em risco o futuro da natureza e, consequentemente, por dependência, do homem que consome cada vez mais. Consumo, nesta discursividade, que se dá de modo isolado, fora do aumento da produção massiva e de uma política explícita de descartabilidade dos produtos fabricados, ou seja, como se ele não fosse construído político-historicamente. Para que este futuro não seja colocado em risco, é preciso organizar a relação do homem com a natureza, por meio de organismos que ultrapassam as soberanias nacionais, desterritorializando o homem como um sujeito político vinculado a um Estado, colocando-o como um indivíduo que deverá se comportar e, portanto, ter responsabilidade global, mundial, frente à natureza, conforme lhe são disponibilizados determinados conhecimentos pedagogizados, em que as coisas a saber são distribuídas e estabilizadas na relação entre a ciência, o Estado e a sociedade. Essa nossa compreensão encontra-se sintetizada no esquema que se segue.

\section{DICOTOMIZAÇÃO CONSTRUÍDA}

Natureza (despatriada)

Meio ambiente

Recursos naturais

Vida do planeta

Ambiental

Futuro
Homem (despatriado)

Ações humanas

Impactos

Alterações profundas

Degradação

Futuro

\section{Comportamento e responsabilidade}

Nossa observação mais incisiva, neste momento, é suspendermos a evidência que se constrói em torno do "futuro", que acaba por apagar - apagamento político fundamental das políticas públicas - o presente, o aqui e o agora. De nosso ponto de vista, projetar o futuro permite apagar as relações sócio-histórico-ideológicas que 
configuram as práticas humanas. E, aqui, observamos que falamos em práticas justamente para não separar o homem da natureza, do meio ambiente, dos recursos naturais.

Continuemos na narrativa da Cartilha, para mostrar a força desta regularidade:

Em 1987, uma Comissão Mundial sobre Meio Ambiente e Desenvolvimento publicou um relatório inovador - "Nosso Futuro Comum" - que trouxe a público o conceito de desenvolvimento sustentável, definido como "a competência da humanidade em garantir que as necessidades do presente sejam atendidas sem comprometer a qualidade de vida das gerações futuras" (p. 5- grifos nossos).

Há, na textualidade do título da reunião de 1987 - "Nosso Futuro Comum" -, a presença da regularidade do apagamento do presente, na projeção do futuro, e de uma evidência de um 'todos' construída pelo pronome possessivo fletido na primeira pessoa do plural e pela presença de "comum" como atributo de "futuro". Esta regularidade ressoa no subtítulo atual da RIO + 20: “O Futuro que Queremos". Há ainda uma importante indicação de um discurso fundador das boas práticas ambientais contemporâneas: o da sustentabilidade. Este discurso nos indica o apagamento do político em 'humanidade' - não há Estados e governos, mas uma categoria genérica que une todo e qualquer homem, além de filiar-se a um discurso moral da benevolência, da compaixão -; e, mais uma vez, a regularidade do apagamento do presente (da qualidade de vida das gerações presentes) em nome das necessidades futuras. Assim pode ser sintetizada nossa compreensão:

\section{DICOTOMIZAÇÃO CONSTRUIIDA}

Necessidades do presente

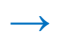

$\varnothing$ qualidade presente
Qualidade de vida das gerações futuras

Merece ainda ser levantada a evidência daquilo que está em torno das "necessidades". Seria preciso minimamente perguntar: necessidades de quem podem ser relativizadas em nome das gerações futuras? Quem está recortado dentro das gerações futuras? Quais necessidades? O que são necessidades? Como se constroem as necessidades? Há necessidades que são atendidas para todos hoje? Enfim, o que se apaga quando se relativiza o presente em nome do futuro de um 'todo' que não tem 
território, não tem Estado, mas caracteriza-se pelo traço comum da natureza humana? ${ }^{6}$ Essa discursividade vai apontando para a direção de um apagamento fundamental: o das relações de força, das relações micro e macro-econômicas, da força do capital que, sim, atravessa fronteiras territoriais, despossuindo e reapropriando-se de práticas cotidianas de significação do espaço material de existências das diversas populações distribuídas de modo desigual pelos territórios nacionais.

Essa humanidade generalizada e, portanto, interditada do sentido político e simbólico dos sujeitos que a constituem, nas suas mais diversas práticas cotidianas de existência, é redita na textualização da Cartilha enquanto um conjunto de indivíduos que precisam mudar seu comportamento, sendo responsáveis pelas consequências dos mesmos. Sigamos um pouco mais a Cartilha:

\section{Comportamento e responsabilidade}

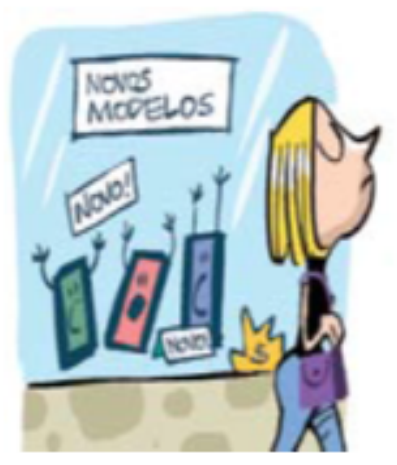

- O excesso de hábitos consumistas é um dos fatores que mais contribuem para o esgotamento das reservas naturais do planeta. Evite substituir desnecessariamente aparelhos que agregam alta tecnologia (celulares, por exemplo) e reduza o consumo de produtos descartáveis

Comportamento e responsabilidade: um discurso que individualiza os modos de apropriação e significação do espaço no qual se vive, apagando as contradições próprias às relações de força e de sentido, às condições materiais de existência, aos modos e meios de produção. Esse discurso, como formulado por Orlandi (2003) ${ }^{7}$, apaga e evita, consequentemente, a necessidade das mudanças de estrutura. Esse discurso explora menos os processos e relações e mais as consequências e resultados. Esvazia o social como estruturante e fica em seus efeitos, desliza para o indivíduo (Idem). O meio

\footnotetext{
"Há pessoas e pessoas", como dissemos, em uma análise de dicionários sobre o termo "analfabeto", em sua dimensão histórica (Silva, 1996). É justo essa uma das direções de sentido que apontamos na compreensão do funcionamento de formas materiais da língua que indicam generalizações.

${ }^{7}$ Orlandi, E. Os Recursos do Futuro: um outro discurso. Revista Multiciência, $\mathrm{n}^{\mathrm{o}} \cdot 1$, outubro de 2003.
} 
ambiente, as mudanças climáticas, nesta discursividade, significam a natureza respondendo ao homem por sua má ação, uma resposta moral - um castigo.

\subsection{No movimento dos sentidos e seus efeitos ideológicos - outras cartilhas}

Pêcheux \& Gadet (2011), ao discutirem movimentos ocorridos no fim da década de 1960 em torno da escola, da família, do meio ambiente e outros, denomina-os de "lutas ideológicas de movimento", chamando a atenção para esse "jogo das heterogeneidades discursivas móveis que geram eventos específicos" em meio a essas lutas ideológicas de movimento.

Ao mesmo tempo em que, sem dúvida, são uma questão de luta de classes no terreno da ideologia, essas lutas devem ser pensadas não como luta entre classes constituídas como tais, mas, em vez disso, como uma série de disputas e embates móveis (no terreno da sexualidade, da vida privada, da educação etc.) pelos processos por meio dos quais a exploração-dominação da classe burguesa se reproduz com adaptações e transformações (PÊCHEUX \& GADET, 2011, p. 97)

Analisando o funcionamento linguístico-discursivo de outras cartilhas referentes ao meio ambiente, dirigidas a públicos distintos, pudemos observar deslizamentos de sentidos que, em um jogo entre o mesmo e o diferente, vão cristalizando certos efeitos de sentidos, tornados evidências, como forma de trabalhar as contradições de uma sociedade em que os laços de integração homem-natureza se tornam tão mais esgarçados quanto mais se falem deles. Nesse sentido, é que podemos falar de uma prática ideológica particular presente em um instrumento de ensinar-aprender e, ao mesmo tempo, de saber-fazer, como as cartilhas; do lugar que elas teriam nessas lutas ideológicas de movimento, pela utilização de um instrumento pedagógico, pelo discurso da divulgação científica.

Nelas, ocorrem as dicotomizações, de que falamos na análise da seção anterior, bem como um apagamento de um dizer sobre/no presente, em que o homem deteriorou uma natureza, imaginariamente, em estado de equilíbrio perfeito, o que podemos observar na Cartilha Semeando um mundo melhor, quando diz que o homem "tem oferecido gás metano CO2", provocando o "efeito estufa", o "lixo industrial”, “o aquecimento global", as “enchentes”, o "lixo doméstico", as "doenças", com suas ações, em uma página ilustrada, com os enunciados que se seguem: 
O homem desmata para abrir pastos.

O gado nos pastos gera gases formadores do EFEITO ESTUFA.

O homem deixa o campo e vai para a cidade.

O homem desbrava a cidade...

O homem desmata a natureza...

A desterritorialização do sujeito, em tempos de globalização também é outra regularidade presente em cartilhas para adultos, que se produz pela reiteração sobreposta de "planeta" a termos como "comunidade", "ações cotidianas". Podemos ler na página inicial de uma cartilha: "O título desta cartilha Semeando um mundo melhor reforça a ideia da responsabilidade de cada um de nós em fazer deste planeta um lugar onde as pessoas possam viver com dignidade, o que somente conquistaremos com ações diárias e com adoção de hábitos ecologicamente corretos" (p. 2). "Portanto, $\operatorname{Sr}(a)$ Cidadão (ã), aproveite a leitura, reflita sobre o seu papel, envolva seus amigos, vizinhos, parentes, colegas de trabalho, faça parte deste movimento e descubra melhorar (sic) a sua qualidade de vida e de todos do planeta. Afinal, saco é um saco pra cidade, pro planeta, pro futuro e pra você", reitera a cartilha do Ministério do Meio Ambiente (2011, p. 07).

Percebe-se, nas cartilhas examinadas, que a noção de "planeta" é central nessa discursividade, em que se deslocam sentidos e atualiza-se uma memória em relação aos laços de pertencimento do sujeito a um território, a uma pátria, nesse momento de reconfiguração das fronteiras mundiais e dos Estados nacionais, em termos geográficos, políticos, sociais.

\footnotetext{
Vivemos em um planeta em que os seres vivos se relacionam entre si e com o ambiente. Logo, quando falamos em meio ambiente,não falamos somente de árvores, bichos e natureza. Meio ambiente é o lugar em que vivemos! Nossa casa, nossa rua, nosso bairro, nossa escola, nossa cidade, estado, país... NOSSO PLANETA! ” (SEMEANDO UM MUNDO MELHOR, p. 3).
}

Nesse contexto, irrompe um discurso sobre o real e sobre as palavras, o que poderíamos chamar de um léxico sobre um domínio de conhecimento, em que ações são locais, individuais, mas o objetivo maior é o "planeta", um "corpo celeste sem luz própria, em órbita ao redor de uma estrela, que possui massa suficiente para que a sua gravidade, além de permitir que assuma forma quase esférica, tenha órbita desimpedida (vale dizer, tenha sido capaz de eliminar outros corpos celestes da vizinhança da sua órbita)" (Houaiss, online). 
Encontramos, nessas cartilhas, um vocabulário estruturado em que conceitos complexos adquirem o formato do discurso pedagógico em que " $\mathrm{x}$ " é " $\mathrm{x}$ ", como no recorte seguinte: “O Ministério do Meio Ambiente (MMA) define consumo consciente como "uma contribuição voluntária, cotidiana e solidária para garantir a sustentabilidade da vida no planeta"” $\left(2011\right.$, p. 09) ${ }^{8}$. Vai se criando, ainda, uma rede de termos e noções, em que se estabelece um modo de ler, criando lugares de interpretação. "Você já percebeu que se fala cada vez mais sobre "reciclagem", "sustentabilidade", "preservação do meio ambiente" e "ecologia"? Estas expressões são palavras-chave para compreender as atuais condições de vida no planeta", de acordo com a cartilha Pense bem da $\operatorname{IPAS}^{9}$ (p. 4).

Mesmo que brevemente, gostaríamos de chamar a atenção para esse modo de fazer circular o conhecimento científico, através de um discurso lexicográfico, trazendo um outro recorte presente na cartilha do IPAS, Pense Bem. O primeiro item do Sumário é "Meio ambiente e dicionário" e, ali, encontramos um "Eco-dicionário", que diz: "Conheça o significado de algumas palavras e expressões muito usadas quando o assunto é meio ambiente" (p. 7),o que é feito através de 21 verbetes, seguindo a ordem alfabética (vão até a letra "r"), a saber: "agroquímicos”, “aquecimento global”, "aterros sanitários", “biodegradável”, “camada de ozônio", “CFC”, “degradável”, "desenvolvimento sustentável”, “ecologia”, educação ambiental”, "eficiência energética", "florestamento", "gestão ambiental”, "lixo orgânico", "lixo reciclável", “poluição", "preservação", "reciclagem”, "recurso ambiental”, "recurso não renovável”, "recurso renovável".

Vemos o dicionário, assim como a cartilha, como um objeto discursivo, que busca dar uma visão integral de uma língua, ou, no caso, de um domínio de conhecimento, produzindo o efeito de completude da representação da língua ou do domínio de conhecimento. Nele estabelece-se uma forma de relação do sujeito com a língua, com o conhecimento, na história; constrói-se um imaginário de língua, de saber para o sujeito de uma dada sociedade, em que é possível dominar, controlar a língua, o conhecimento sobre " $\mathrm{x}$ " Interessa-nos, pois, compreender como os sentidos das palavras

\footnotetext{
8 Apesar das aspas, não há indicação da fonte. Aliás, essa é uma regularidade nas definições.

9 “Formada por grandes empresas, como Bunge, Carrefour, Grupo JD, Klabin, Nestlé e Sadia, a IPAS conta também com a participação da IPD - Organics Brasil, da Sociedade Rural Brasileira, da organização não governamental The Nature Conservancy (TNC) e das instituições de ensino e pesquisa Escola de Marketing Industrial e Pensa/FEA-USP. Em comum eles têm o objetivo de promover modelos mais sustentáveis que envolvam toda a cadeia de alimentos" (p. 3).
} 
aí se produzem, de acordo com as diferentes formações discursivas ${ }^{10}$, que correspondem a diferentes posições do sujeito em face da ideologia (ORLANDI, 2002).

A representação fiel do dicionário nos dá uma língua (imaginária) homogênea, perfeita, completa, sem falhas, de todos nós. Do mesmo modo, o dicionário parece não ter ideologia, sendo "neutro", ou melhor, tendo a neutralidade (universalidade) da língua. Como não tem marcas ideológicas, sua ideologia é justamente não se marcar ideologicamente. Só um trabalho discursivo pode nos situar ideologicamente em relação aos efeitos do dicionário, observando-se, em sua constituição, o que chamamos as formas materiais, indícios dos processos discursivos, linguístico-históricos (ORLANDI, 2002, p. 108).

Observamos que o verbete no "Eco-dicionário" é formado apenas pela definição da palavra. Para Nunes (2003, p. 16), “os sentidos da definição, de um ponto de vista dicursivo, não são detectáveis no interior do enunciado definidor, tomado isoladamente, mas, sim, na relação que esse enunciado estabelece com outros em determinadas formações discursivas. Assim, os enunciados definidores são remetidos às posições ideológicas em jogo...”. Tomaremos, apenas, um verbete, diríamos central - pois, referese a um modelo econômico da formação social capitalista -, para que o leitor, retomando a análise que fizemos da Cartilha Ilustrada sobre Economia Verde, Desenvolvimento Sustentável e Erradicação da Pobreza- O Futuro que Queremos, elaborada pelo INPE, possa refletir sobre termos e enunciados de um léxico que se constrói pela sua reiteração em diferentes discursividades, trabalhando as contradições da sociedade.

\begin{abstract}
Desenvolvimento sustentável
Modelo de desenvolvimento que utiliza recursos da natureza, sem destruí-los, para um crescimento econômico que também aprimore a qualidade de vida das pessoas e respeite a natureza, mantendo a possibilidade de as próximas gerações suprirem suas próprias necessidades. (IPAS, p. 7)
\end{abstract}

Essas e outras questões devem ser, então, pensadas em uma análise discursiva mais exaustiva do "Eco-dicionário", o que não faremos aqui, dados os limites deste artigo. Nosso objetivo foi o de sinalizar para questões implicadas ao se tomar o dicionário como referência para a circulação do conhecimento, e, mais, no interior de uma cartilha.

\footnotetext{
${ }^{10}$ De acordo com Pêcheux (1988), a formação discursiva é "aquilo que, numa formação ideológica dada, isto é, a partir de uma posição dada numa conjuntura dada, determinada pelo estado da luta de classes, determina o que pode e deve ser dito (articulado sob a forma de uma arenga, de um sermão, de um panfleto, de uma exposição, de um programa etc.)" (p. 160 - grifos do autor).
} 


\section{Para concluir}

Neste artigo, vimos que a divulgação científica funciona, entre outras instâncias, por uma articulação entre o pedagógico, o científico, o linguístico, apagando, quase sempre, a espessura política daquilo que se ensina e divulga. A ciência também, em grande parte, diríamos. O que pudemos compreender, a partir das análises feitas, é que um dos elementos estruturantes do discurso sobre o meio ambiente, no espaço da circulação das informações, é o de que é preciso mudar o comportamento do homem, para que ele aja com responsabilidade para com o planeta em última instância. $\mathrm{Na}$ individualização da "solução" para os "problemas", apaga-se a história, apaga-se o político, promovendo, conforme já apontou Orlandi (2003), condições de produção para um discurso reformista que silencia a possibilidade de uma outra ordem nas relações de força e de sentidos instauradas por uma formação ideológica neoliberal. Discursividade esta que estabiliza (tornando visível e naturalizado), a partir de uma articulação entre a ciência e o trabalho social da imprensa, em outras palavras dentro de um discurso de divulgação científica, o modo de configuração daquilo que se tornou, modernamente, um problema social: o meio-ambiente. Um meio ambiente, do qual o homem está quase sempre excluído, mas que é de sua responsabilidade preservá-lo, depois de tê-lo destruído (sua degradação é feita pelo homem e individualmente), e não das condições materiais de existência das sociedades contemporâneas que têm no Estado o espaço das regulamentações e negociações da ordem jurídica e política. Apaga-se o Estado e as contradições inerentes ao atual jogo de forças políticas e econômicas. E esse apagamento, disciplinarizado, pedagogicamente, se instala como um discurso disponível e logicamente estabilizado em nossa sociedade.

Nesse ensinar-aprender, nesse saber-fazer, vai se construindo, assim, uma sustentação para os sentidos de 'meio ambiente', na indistinção de argumentos configurados por um discurso científico e um discurso moral, no modo próprio de funcionamento de um discurso pedagógico, projetando no indivíduo a responsabilidade por uma alteração de comportamento. Uma discursividade que separa o homem de seu meio, que apaga o presente falando de um futuro, que torna cada um em todos, distinguindo alguns em meio a todos.

\section{Referências Bibliográficas}

ALTHUSSER, L. Ideologia e aparelhos ideológicos do Estado. Trad. Joaquim José de Moura Ramos. Lisboa: Editorial Presença, 1980. 
AUROUX, S. A revolução tecnológica da gramatização. Trad. Eni P. Orlandi. Campinas: Editora da Unicamp, 1992.

FERREIRA, A. B. de H. Novo dicionário AURÉLIO. $1^{\mathrm{a}}$ edição, 14 impressão. Rio de Janeiro: Nova Fronteira, 1975.

FRIGOTTO, G. A relação da educação profissional e tecnológica com a universalização da educação básica. Educação e Sociedade, vol. 28, n. 100 - Especial. Campinas, SP, out. 2007, p. 1129-1152.

HENRY, P. Os fundamentos teóricos da "Análise Automática do Discurso" de Michel Pêcheux. In. Gadet, F. \& Hak, T. (orgs.) Por uma análise automática do Discurso: uma introdução à obra de Michel Pêcheux. Trad. Bethania Mariani ... [et al.]. Campinas: Editora da Unicamp, 1990, 13-38.

HERBERT, T. Reflexões sobre a situação teórica das Ciências Sociais e, especialmente, da Psicologia Social. Trad. Mariza Vieira da Silva e Laura A. Perrella Parisi. In: Orlandi, E. P. (org.). Análise de Discurso: Michel Pêcheux, 2011, p. 21-54.

HOUAISS, A. Grande Dicionário HOUAISS Beta da língua portuguesa. Disponível em http://houaiss.uol.com.br. Acesso em 19 de abril de 2013.

MAINGUENEAU, D. Novas tendências em análise do discurso. Trad. Freda Indursky. Campinas: Pontes, 1989.

MORTATTI, M. do R. L. Cartilha de alfabetização e cultura escolar: Um pacto secular. Cadernos Cedes, Ano XX, No 52, novembro/2000, p. 41-54.

NÓBREGA, M. da. Cartas do Brasil. Cartas Jesuíticas I. Coleção Reconquista do Brasil ( $2^{\text {a }}$ série). Vol. 147. Belo Horizonte: Editora Itatiaia; São Paulo: Editora da Universidade de São Paulo, 1988.

NUNES, J. H. Definição lexicográfica e discurso. Línguas e Instrumentos Linguísticos, No. 11. Campinas: Pontes, 203, p. 9-30.

ORLANDI, E. (Org.). O Sentido Público no Espaço Urbano: a cidade atravessada. 1ed. Campinas: Pontes/Labeurb, 2001.

ORLANDI, E. P. Língua e conhecimento linguístico: para uma História das Ideias no Brasil. São Paulo: Cortez, 2002.

ORLANDI, E. Os Recursos do Futuro: um outro discurso. Revista Multiciência, $\mathrm{n}^{\mathrm{o}} \cdot 1$, outubro de 2003, p.1-7.

PÊCHEUX, M. Semântica e discurso: uma crítica à afirmação do óbvio. Trad. Eni P. Orlandi ... et al. Campinas, Editora da Unicamp, 1988.

PÊCHEUX, M. [1969] Análise automática do discurso. In. Gadet, F. \& Hak, T. (orgs.) Por uma análise automática do Discurso: uma introdução à obra de Michel Pêcheux. Trad. Bethania Mariani ... [et al.]. Campinas: Editora da Unicamp, 1990, 61-162.

PÊCHEUX, M. Discurso: estrutura ou acontecimento. Trad. Eni P. Orlandi. Campinas: Pontes, 1990. 
PÊCHEUX, M. \& Gadet, F. A língua inatingível. In: Orlandi, E. P. (Org.) Análise de Discurso: Michel Pêcheux. Trad. Sérgio Augusto Freire de Souza. Campinas; Pontes, 2011, p. 93-105.

PFEIFFER, C. R. C. Cidade e Sujeito Escolarizado. In: Eni de Lourdes Puccinelli Orlandi. (Org.). O Sentido Público no Espaço Urbano: a cidade atravessada. 1ed.Campinas: Pontes/Labeurb, 2001, p. 29-33.

SILVA, M. V. da As cartilhas na sociedade do conhecimento. Entremeios: revista de estudos do discurso. No. 8. Pouso Alegre, MG: Univás, jan/2014.

SILVA, M. V. da. História da alfabetização no Brasil: a constituição de sentidos e do sujeito da escolarização. Tese de doutorado. Campinas: IEL/UNICAMP, 1998.

SILVA, M. V. da. O dicionário e o processo de identificação do sujeito-analfabeto. In: Guimarães, E. \& Orlandi, E. P. Língua e cidadania: o Português do Brasil. Campinas, Pontes, 1996, 151-162.

VINCENT, G.; Lahire, B.; Thin, D. Sur l'histoire et la théorie de la forme scolaire. In : Vincent, G. (Org.) L'Éducation prisonnière de la forme scolaire? Scolarisation et socialisation dans les societies industrielles. Lyon: Presses Universitaires de Lyon, 1994, 11-48.

VOJNIAK, Fernando. O império das primeiras letras: uma história da institucionalização da cartilha de alfabetização no século XIX. Tese de doutorado. Universidade Federal de Santa Catarina. Florianopólis, SC: 2012.

Cartilhas

BRASIL. Ministério do Meio Ambiente. Orientações sobre o consumo consciente e propostas para redução de sacolas plásticas pelos consumidores. Brasília: Ministério do Meio Ambiente, 2011. Disponível em: http://www.mma.gov.br/estruturas/234 I_arquivos/cartilha_3_consumidores_234.pdf.

Instituto Camargo Corrêa. Semeando um mundo melhor. Disponível em: http://www.institutocamargocorrea.org.br/Documents/CartilhaSemeandoumMundoMel hor.pdf.

INPE - Instituto Nacional de Pesquisas Espaciais. Cartilha ilustrada sobre Economia verde, desenvolvimento sustentável e erradicação da pobreza - O FUTURO QUE QUEREMOS. Disponível em www.inpe.br/50anos.

IPAS - Iniciativa Pró-Alimento Sustentável. Pense bem - Meio Ambiente. Disponível em: http://www.bunge.com.br/sustentabilidade/2009/port/download/pense bem_meio _ambiente.pdf

SÃO PAUlO. Saúde Cidadão. Ministério Público de São Paulo, 2013. Disponível em: http://www.mpsp.mp.br/portal/page/portal/Cartilhas/Saude_Cidadao2.pdf .

SENAC - Serviço Nacional de Aprendizagem Comercial; Regional de Minas Gerais. Meio ambiente - dicas de atitudes conscientes e sustentáveis. Disponível em: http://www.mma.gov.br/estruturas/234/_arquivos/cartilha_3_consumidores_234.pdf Acesso em 12.09.2014. 

Para citar essa obra:

SILVA, M. V; PFEIFFER, C. C. A pedagogização do espaço urbano. In: RUA [online]. 2014, Edição Especial - ISSN 1413-2109. Consultada no Portal Labeurb - Revista do Laboratório de Estudos Urbanos do Núcleo de Desenvolvimento da Criatividade. http://www.labeurb.unicamp.br/rua/

Capa: INPE - Instituto Nacional de Pesquisas Espaciais. Cartilha ilustrada sobre Economia verde, desenvolvimento sustentável e erradicação da pobreza - $O$ FUTURO QUE QUEREMOS. Disponível em www.inpe.br/50anos.

Laboratório de Estudos Urbanos - LABEURB

Núcleo de Desenvolvimento da Criatividade - NUDECRI

Universidade Estadual de Campinas - UNICAMP

http://www.labeurb.unicamp.br/

Endereço:

LABEURB - LABORATÓRIO DE ESTUDOS URBANOS

UNICAMP/COCEN / NUDECRI

CAIXA POSTAL 6166

Campinas/SP - Brasil

CEP 13083-892

Fone/ Fax: (19) 3521-7900

Contato: http://www.labeurb.unicamp.br/contato 